\title{
НОВЫЕ ПОДХОДЫ В СОЦИАЛЬНОМ ПОЗНАНИИ: ПРОБЛЕМЫ И ПЕРСПЕКТИВЫ
}

\section{И.А. Донникова}

Исследование самоорганизующихся систем в последние десятилетия XX века сопровождалось развитием новых подходов к изучению различных сфер знания. Не стали исключением в этом отношении и социально-гуманитарные науки. Для исследования объектов социальной природы в 90-х гг. возникло направление, которое может быть обозначено как «социальная синергетика». В понимании предмета социальной синергетики между исследователями нет принципиальных разногласий - они видят его в исследовании общих закономерностей социальной самоорганизации, то есть взаимозависимости социального порядка и социального хаоса. Однако в понимании сущности синергетического подхода к исследованию социальньх процессов такого единства нет. Социосинергетика объединяет исследования в области социологии, политологии, экономики, демографии, истории, педагогики, психологии, культурологии, искусствоведения и т.д. По сути, она развивается как множество «социосинергетик»- прикладных дисциплин, возникших на стыке синергетики и определенной социально-гуманитарной науки. Отсюда вполне понятны различия между исследовательскими приемами, которые складываются в рамках каждой науки, но каждый из которых, тем не менее, носит название «синергетический подход».

Следует также добавить, что, едва заявив о себе как о самостоятельном направлении, социосинергетика сразу же стала заложницей понятия «социальное», ограничив свое проблемное поле анализом отдельных сфер общественной жизни, вполне определенных социальных процессов - политических, экономических, демографических, образо-

Актуальні проблеми духовності: 
вательных и т.д. Выделяя в социальной реальности различные элементы и структуры и рассматривая их динамику как нелинейный процесс, социосинергетика, по сути, исследует локальные механизмы или способы социальной самоорганизации. Так, совершенно очевидно, что механизмы самоорганизации человеческих сообществ отличны от процессов самоорганизации, которые развертываются на уровне личностного бытия, психики, языка, телесности человека и т. д. В результате в своем современном содержании социальная синергетика представлена множеством концепций, которые раскрывают самоорганизационные процессы, развертывающиеся на различных уровнях социума, но не раскрывают универсальный механизм социальной самоорганизации, охватывающий все формы социального.

Разнообразие точек зрения на сущность социальных изменений и методологических подходов к их изучению в значительной степени обусловлено и неоднозначностью отношений между социальной философией и социологией. Не останавливаясь детально на этом вопросе, отметим, что в понимании проблемного поля этих наук, методологических приемов, понятийной базы и т. д. можно выделить, по крайней мере, три сложившихся подхода: социальная философия как метатеория социологии; социальная философия как теоретическая социология; и, наконец, признание отсутствия каких-либо отличий между социальной философией и социологией как не имеющих принципиального значения в постмодернистском научном дискурсе (см. подробно: [6, с. 329-330]).

Имеющая место неоднозначность не может не отражаться на трактовках понятия «социальное», которые располагаются в диапазоне от узкосоциологического - общество с социальными структурами, институтами, отношениями и т. д., до философского - социальное бытие. В предлагаемых подходах к решению проблем современного социального познания явно доминирует социологический аспект. На общем фоне синергетического «бума» ощущается дефицит философских исследований, которые с характерным для философии уровнем теоретичности и абстрагирования сформировали бы теоретическую и методологическую базу социосинергетики. Именно философия в силах упорядочить хаос концепций и теорий, который наблюдается в современном познании, поскольку она призвана исследовать не социальные отношения, социальные действия, социальные функции, институты, общности и т. д., а социальное бытие. «Общество и его элементы как проявления бытия и разновидности сущего является особенным, уникальным и неповторимым предметом социальной философии» [6, с. 332]. Тем са- 
мым, философский анализ позволяет конкретизировать предмет социальной синергетики - самоорганизующееся социальное бытие. Поскольку речь идет о социальном бытии, а не об обществе (в его социологическом понимании), исследование процессов самоорганизации, на наш взгляд, должно осуществляться в системе отношений «природа - человек - общество», охватывая не только межиндивидные и иные внутрисоциальные взаимодействия, социальные связи и структуры, но и отношение «общество - природа» (учитывая открытость социального бытия).

Следует также добавить, что социосинергетика, преимущественно дублируя социологический взгляд на общество, по сути, становится новомодной отраслью социологического знания, справедливо вызывающей скептическое к себе отношение. Между тем, как синергетика для современной науки, так и социосинергетика для социального познания обладают значительным эвристическим потенциалом, способным вывести познание на новый уровень. В социальном познании использование идей синергетики позволяет по-иному взглянуть на социальную реальность, открыв и объяснив в ней ранее скрытые стороны и свойства. Такое изменение познавательной позиции в значительной степени связано с пониманием сущности и возможностей синергетического подхода. Прежде чем мы попытаемся раскрыть его специфику, отметим, что исследовательская программа, которая возникает в системе синергетических представлений, не является «изобретением» собственно синергетики. Подобно тому, как в мировоззренческом плане синергетика - это переоткрытие мира, в методологическом она преемница способов познания, которые сложились в различных науках. Действительно, по справедливому замечанию В.С. Степина, «синергетика не открывала ни иерархической связанности уровней организации в саморазвивающихся системах, ни наличие в них относительно автономных подсистем, ни прямых и обратных связей между уровнями, ни становление новых уровней данной системы в процессе ее развития» $[9$, с.65]. Все это она заимствовала у своих предшественников - общей теории систем, кибернетики, теории катастроф, теории автопоэзиса живых систем и др. Именно в этих научных направлениях были сформированы методологические подходы, получившие синтезированное осмысление в синергетике - выделение системных объектов, абстрагированных от их «субстратов», анализ способов связей между элементами, приводящих к образованию этих объектов. Основу междисциплинарной методологии составили теория систем и кибернетика, которые, в свою очередь, способствовали становлению синергети- 
ческого подхода.

Методологический путь, предложенный теорией систем, оказался настолько глубоким и фундаментальным, что многие исследователи склонны рассматривать синергетику как один из видов системного анализа. По мнению К.Х. Делокарова, «синергетика продолжает традицию тех наук, которые возникают при решении ... проблем, связанных с разрушением одних форм упорядоченности и возникновением других, независимо от того, в какой предметной области это происходит. В этом смысле синергетика больше похожа на общую теорию систем, нежели на ту или иную конкретную науку» [3, с. 66]. В ситуации «вызова познанию», которую создала синергетика, эта похожесть стала поводом для оживленной научной дискуссии синергетики с такой мощной методологией как системный подход. Значительное число исследователей рассматривает синергетику как новую системную парадигму, констатируя формирование системно-синергетического подхода. Так, В.С. Степин указывает на границы применимости синергетики и отмечает, что она не отменяет и не заменяет системные исследования, более того, конкретные модели систем создаются в синергетике с учетом понятийного аппарата системных исследований $[9$, с. 65]. Холистский подход, который презентует синергетика, только в связи с системным может дать полное описание саморазвивающихся систем. «В ситуации неустойчивости фазового перехода интегральное описание в терминах нелинейных сред оказывается наиболее эффективным. Но после становления нового уровня организации и формирования новых параметров порядка описание динамики системы предполагает ... анализ новых свойств элементов и подсистем, возникших в результате предшествующей системной трансформации» [9, с.67].

В новой научной парадигме обновление традиционных методологических подходов неизбежно. В отношении системного подхода такое обновление также необходимо, поскольку в контексте постнеклассической науки все более очевидными становятся «границы» его когнитивных возможностей. Генетически связанный с биологией, системный подход концентрирует внимание на устойчивых, гомеостатических состояниях развития системы, на возможности поддержания таких состояний. Поэтому, рассматривая систему в развитии, эволюции, системный подход, прежде всего, выявляет основания сохранения ее целостности, то есть стабильности. В тоже время синергетика интересуется процессами переструктурирования, возникающими в результате срабатывания бифуркационных механизмов и руководствуется установкой о постоянности и неизбежности новых изменений. Иными сло- 
вами, если системный подход позволяет ответить на вопрос, как и благодаря чему сохраняется система, то синергетический - как и благодаря чему эволюционизирует система.

Оперируя понятием «сложная система», системный подход идет по пути упрощения системы (выделяя ее части и структуры), иными словами, следует логике упрощения, в то время как задача современной науки - объяснить механизмы возникновения и наращивания сложности. Единицей описания в системном подходе является отдельный элемент системы, который соотносится с ней как «часть» и «елое». В облике синергетики постнеклассическая наука концентрирует внимание на когерентном взаимодействии, то есть на сетях взаимодействий, в которые включен данный элемент. В связи с этим, переосмысливая соотношение части и целого (элементов и системы), в синергетике преимущественно используется понятие «среда», которое более адекватно отражает постоянно меняющиеся связи и отношения внутри системы, порождающие необходимый для ее эволюции хаос.

Тем самым, если в системном подходе свойства приписываются индивидуальному объекту, в синергетике-ансамблям, множествам объектов. «Иными словами, за результат работы, способность быть наделёнными теми или иными свойствами "отвечают"не отдельные элементы системы, а их коллективные взаимодействия - согласованности, синхронизации, когерентности» [1, с. 109]. Добавим к этому, что вопреки мнению многих сторонников системного подхода, синергетика не отказывается от понятия системы, а скорее наполняет его новым содержанием. Изучая механизмы самоорганизации, синергетика ищет ответы, по крайней мере, на два вопроса: «что выступает источником самоизменения системы?» и «что способствует сохранению системы в процессе изменения?».

Таким образом, несмотря на выделенные оппозиции, нельзя согласиться с теми исследователями, которые утверждают, что синергетика заменяет и отрицает теорию систем. Очевидно, речь может идти как об обновлении системного подхода (формировании системно-синергетического), так и о возможности самостоятельного функционирования синергетического подхода (при обосновании необходимости такого функционирования). В ситуации методологического плюрализма, которая сложилась в современной науке и, в частности, социальном познании, ценностью и важностью обладает любая инновация, которая может стать генератором новых, порой неожиданных идей. Поэтому, на наш взгляд, синергетический подход имеет свое поле приложения в социальном познании и может быть использован, наряду с 
системным, для решения вполне определенных задач. В данном случае мы полностью разделяем мнение Е.Н.Князевой, которая не исключает существование у синергетики определенных хронологических границ. Синергетика может сойти с исторической сцены, как это произошло с кибернетикой, однако она представляет собой тип «фермента» или «катализатора», который не заменяет базовые научные дисциплины, но стимулирует развитие знания в их рамках [7, с.46-47]. На наш взгляд, современное социальное познание особенно нуждается в таком катализаторе.

Исследователи отмечают, что синергетика универсальна на макроуровне, на уровне осознания сценариев развития сложных систем. В отношении социального познания необходимо уточнить, что макроуровень социосинергетических исследований отличен от макроуровня социологии. Он не соотносится только с коллективными, надличностными формами социального бытия; он «подвижен» в том смысле, что может быть представлен любой социальной целостностью: будь это индивид, этническая, профессиональная или иная общность, социальный институт, общество в целом. Соответственно, по отношению к выбранному макроуровню микроуровень представлен элементами, связями и отношениями, складывающимися внутри выделяемой целостности. Как следствие, макроуровень синергетических исследований не разъединяет социальную реальность на фрагменты, не противопоставляет себя микроуровню, а изначально представляет ее как целостность, поскольку процессы самоорганизации имеют универсальную природу и, начинаясь в виде флуктуаций на микроуровне, охватывают все социальное бытие. При синергетическом анализе границы между уровнями утрачивают жесткие очертания, поскольку само существование этих уровней - результат самоорганизационных процессов.

Кроме того, синергетический анализ позволяет связать социальную реальность с более широким контекстом, встроить ее в окружающее природное пространство. Социальное бытие предстает одним из уровней самоорганизующегося мира, способ самоорганизации которого, тем не менее, качественно отличается от природного. Понять, в чем заключается это отличие, представляется возможным при изучении социальности «извне», когда существующий порядок (в данном случае социальный порядок), по словам Г. Хакена, становится «наблюдаемым». В таком случае Вселенная, природа, в целостности которых рождается социальное бытие, представляют метауровень, собственно социум - макроуровень. При таком анализе социального бытия становится возможным выявление сущности социальной самоорганизации 
как специфически человеческого механизма развития, универсального по сути (пронизывающего все уровни социального бытия), но приобретающего специфические формы в различных социальных целостностях.

Едва ли не единственная в современных научных исследованиях формулировка синергетического подхода принадлежит И.С. Добронравовой, которая, анализируя методологический потенциал синергетики, связывает его с возможностью теоретической реконструкции самоорганизационных процессов, с переинтерпретацией известных ранее явлений как феноменов самоорганизации [4, с. 80]. На наш взгляд, понятие «теоретическая реконструкция» вполне заменимо понятием «модель», которое в данном случае следует трактовать предельно широко - как любую форму объективизации, опредмечивания идеального образа объекта [5, с. 178]. Кроме возможности проведения различного рода экспериментов, модель выступает, прежде всего, программой действия по предстоящему построению смоделированного объекта. В этом смысле любая форма познания носит форму моделирования. Применение моделей - одно из отличительных свойств целенаправленной деятельности человека, отличающей ее от инстинктивного поведения животных [5, с. 179$]$.

Уместным будет сослаться и на точку зрения А. Мостяева, который отмечает, что цель подобного моделирования - с достаточной корректностью понять окружающие события, доступную восприятию часть действительности. Модель позволяет преодолеть противоположность между методами «объяснения» и методами «понимания», поскольку представляет собой интерпретацию реальности, а не абсолютное знание о ней. «Поэтому следует, используя термин, предложенный Э. Гуссерлем, подчеркнуть, что модель коррелирует с реальностью, а не отображает ее... В понятии „корреляция“ ... выражены и момент совпадения модели и предмета, и момент творческого привнесения человеком в объект своих интенционных установок и интерпретативных возможностей» $[8$, с. 18-19]. В.Г.Буданов отмечает, что речь идет об «особом средстве теоретизации», которое может быть использовано и в гуманитарном знании - моделировании нелинейной динамики, в котором физика, отражающая модельно природу, дополняется философской рефлексией. Главная задача такого моделирования - избежать крайнего физикализма и редукционизма при переносе моделей естествознания в гуманитарную сферу и сохранить конструктивность модельного подхода в диалоге с новой реальностью [2].

Исходя из такого понимания модели представляется правомерным 
использование этого понятия как в онтологических построениях синергетики (когда речь идет о синергетической модели мира), так и в определении сущности синергетического подхода. Интерпретируя мысль И.С. Добронравовой, его можно определить как моделирование самоорганизационного процесса в определенной системе путем распознавания его в известных феноменах, в том числе и социальных.

Необходимо заметить, что в социальном познании использование синергетического подхода часто сводится к формальному переносу схемы нелинейной динамики на те или иные социальные процессы, мало что добавляя в понимание их сути. Действительно, теоретические положения синергетики схематизируют самоорганизационный процесс, выделяя в нем три основные стадии: предбифуркационную, характеризующуюся возрастанием флуктуаций, что сопровождается формированием спектра аттракторов; бифуркационную, в которой происходит синтез двух противоположных процессов - деструктуризации и локализации, осуществляется выбор одного из множества аттракторов; и послебифуркационную, связанную с формированием нового параметра порядка, переходом системы в фазу относительно устойчивого развития. Собственно самоорганизация происходит в точке бифуркации, в то время как две другие стадии - это «погружение в хаос» и затем «выход из хаоса»на относительно устойчивое развитие.

Сосредотачиваясь на стадиях самоорганизационного процесса, исследователи часто упускают из виду процессы внутри анализируемой системы. Между тем, синергетический подход предполагает, прежде всего, анализ взаимодействия элементов (подсистем) внутри системы, которое и определяет направленность ее эволюции. Иными словами, теоретическая реконструкция самоорганизационного процесса должна начинаться с поиска оснований нелинейности данной системы, анализа микроуроня (уровня флуктуаций) и через выявление механизмов когерентного взаимодействия подсистем выходить на макроуровень. В таком случае схема самоорганизационного процесса становится не самоцелью, а ожидаемым итогом проводимого анализа.

Таким образом, синергетический подход предполагает выявление механизмов согласования, когерентности процессов самоорганизации, которые развертываются на уровнях элементов сложных систем и определяют их нелинейную эволюцию. Именно механизмы согласования позволяют раскрыть возникновение порядка из хаоса, выявить творческие потенции исследуемой системы. Применительно к социальному бытию речь может идти о выявлении способов согласования множества индивидуальных жизненных проявлений, которые представ- 
ляют собой уровень социальных флуктуаций и, находясь в когерентном взаимодействии, создают неустойчивое и нелинейное социальное бытие, способное к самоорганизации.

\section{1 Литература}

[1] Аршинов В.И., Данилов Ю.А., Тарасенко В.В. Методология сетевого мышления: феномен самоорганизации // Онтология и эпистемология синергетики. - М., 1997. - С. 101-119.

[2] Буданов В.Г. Синергетика: история, принципы, современностьhttp://spkurdyumov.narod.ru/SinBud.htm.

[3] Делокаров К.X. К вопросу о применении идей синергетики к изучению социокультурных процессов // Культура и культурная политика. Материалы научно-методологического семинара. Вып. 1. Синергетическая концепция культурно-исторического процесса М.С. Кагана. - М.: Изд-во РАГС, 2005. - С. 65-72.

[4] Добронравова И.С. Синергетика как общенаучная исследовательская программа // Синергетическая парадигма: когнитивно-коммуникативные стратегии современного научного познания - М.: Прогресс-Традиция, 2004.- С. 79-87.

[5] Ивакин А.И. Диалектическая философия.-Одесса: Феникс; Сумы: Университетская книга; М.: ТрансЛит, 2007.

[6] Кулєшов О.В. Буття як проблема соціальної філософії // Актуальні проблеми духовності.-Вип. 8.-Кривий Ріг: Видавничий дім. - 2007. - С. 329-341.

[7] Князева E.H. Трансдисциплинарные когнитивные стратегии в науке будущего // Вызов познанию. Стратегии развития науки в современном мире. - М.: Наука, 2004. - С. 29-48.

[8] Мостяев О. Світ як затриманий розпад: роздуми щодо еволющії відкритих систем. - К: МП Леся, 2004.

[9] Степин В.C. Синергетика и системный анализ // Синергетическая парадигма: когнитивно-коммуникативные стратегии современного научного познания. - М.: Прогресс-Традиция, 2004.C. 59-77. 